\title{
PEMBENTUKAN INGO (KATA SANDI) DALAM DUNIA KEPOLISIAN JEPANG
}

\author{
Oleh: \\ Taqdir \\ Fakultas Ilmu Budaya Universitas Hasanuddin
}

\begin{abstract}
The purposeof this studywas to determinethe structure offormingingo(argot), especially in the Japanesepolice. The data werederivedfromthe expressions(argot) that isoften used inthe Japanesepolice. The analysis inthis studyrefersto the theory ofthe formation ofthedividingMikatastructureformationin tensections, while analysisrefersto the theoryof meaningArgot'sSanada.Finding in this study is thatthe formation ofthe policeargotinJapaninclude the establishment ofshorteningsyllables, syllableexchange, a similar shape, association, movement, imagery, soundthe same, the gameof letters, symbols, andanalogies.
\end{abstract}

\section{PENDAHULUAN}

Si jago merah berhasil melahap beberapa rumah dan dia sedang koma di rumah sakit adalah kalimat yang sering kita jumpai dalam berbagai macam pemberitaan di media massa. Kalimat tersebut tentunya akan sulit dimengerti bagi orang yang asing yang belum mengetahui istilah-istilah yang digunakan dalam pemberitaan tersebut. Sama halnya dalam bahasa Jepang sering dijumpai berbagai macam istilahistilah yang digunakan dalam komunitas masyarakat tertentu, seperti dalam dunia kepolisian, media massa, serta kelompokkelompok anti sosial seperti yakuza, pencuri dan lain sebagainya. Tentunya kata-kata yang mereka gunakan sebagian besar bukan hanya sulit dimengerti khususnya bagi kita sebagai pembelajar asing, tetapi juga bagi penutur bahasa tersebut dalam hal ini orang Jepang sendiri. Seperti halnya dalam dunia kepolisian sering dijumpai istilah-istilah asing yang tidak akrab ditelinga penutur bahasa tersebut atau istilah yang melenceng dari makna sebenarnya, seperti kata hoshi, dalam makna sebenranya berarti "bintang" tetapi dalam di dalam istilah kepolisan diartikan sebagai "pelaku kejahatan”. Serta dalam kelompok yakuza menggunakan istilah chaku untuk menyebutkan "pistol” tidak menggunakan kenjuu

Bahasa atau istilah yang digunakan dalam komunitas masyarakat tersebut dikenal dengan istilah shudango (bahasa komunal). Shudango adalah kosa kata khas yang digunakan

${ }^{*}$ Penulis Korespondensi.

E-mail: taadir@fs.unhas.ac.id dalam suatu kelompok masyarakat tertentu atau dalam kelompok spesiliasi tertentu (Sanada 1992: 25). Lebih lanjut Shinoda membagi shudango ke dalam beberapa bagian yaitu, seigyougo (istilah dalam dunia produksi), shukubago (istilah dalam tempat kerja), semmongo (istilah dalam kelompok keahlian seperti fashion, arsitek dll), jutsugo (istilah dalam dunia akademis), ingo (kata sandi) dan surangu (slang).

Kata-kata atau istilah dalam seigyogo, shukubago, semmongo dan jutsugo digunakan untuk mengefisiensikan atau untuk kepentingan pekerjaan dalam kelompok-kelompok tersebut, sedangkan istilah atau kata-kata dalam ingo atau surangu digunakan untuk menjaga kerahasiaan kelompok-kelompok mereka.

Adapun tujuan dari tulisan ini adalah untuk mengetahui struktur pembentukan kata sandi (ingo) dalam dunia kepolisian Jepang.

\section{METODE PENELITIAN}

Penelitian ini merupakan penelitian. Sudaryanto (1992: 62) menyatakan bahwa penelitian deskriptif merupakan penelitian yang dilakukan semata-mata hanya berdasarkan fakta yang ada atau fenomena yang memang secara empiris hidup pada penutur-penuturnya, sehingga yang dihasilkan atau yang dicatat berupa perian bahasa yang biasa dikatakan sifatnya seperti potret: paparan seperti adanya.

Dalam mendapatkan hasil akhir dalam penelitian ini dilakukan dua tahap, yakni pengumpulan data dan analisis data. 
Berikut ini akan dipaparkan metode dan teknik yang dilakukan dalam tahapantahapan tersebut.

Pengumpulan data dalam penelitian ini menggunakan metode simak dengan teknik catat. Menurut Mahsun (2001: 92) metode simak adalah metode untuk memperoleh data dengan cara menyimak penggunaan bahasa yang tidak hanya berkaitan dengan penggunaan bahasa secara lisan, tetapi juga penggunaan bahasa secara tertulis. Data yang berhubungan dengan penelitian ini dicatat dan diklasifikasikan berdasarkan bentuknya. Sudaryanto (1993: 135) menyatakan bahwa teknik catat adalah pencatatan yang dilakukan pada kartu data yang segera dilanjutkan dengan klasifikasi. Data yang telah terkumpul dianalisis berdasarkan klasifikasi pembentukan ingo sesuai teori Mikami.

\subsection{Pengertian Ingo}

Ingo adalah kosa kata atau istilah dalam suatu kelompok yang digunakan untuk menjaga kerahasiaan dalam kelompok tersebut (Sanada, 1992: 27). Kosa kata atau istilah dalam kelompok spesialis tertentu dan kosa kata tersebut hanya digunakan dalam kelompok tersebut, istilah atau kosa-kata ini digunakan untuk mempertinggi rasa kesadaran dalam kelompok atau untuk menjaga kerahasian dari pihak luar. Kosa kata yang mereka gunakan secara mendasar tidak diketahui oleh orang diluar kelompok mereka.

Kosa kata ini tidak terbatas hanya digunakan dalam kelompok-kelompok anti sosial seperti yakuza, pencuri dan lain sebagainya, tetapi juga digunakan kelompok-kelompok masyarakat umum seperti polisi, dokter dan apoteker. Mereka menggunakan ingo apabila berbicara dengan teman sekolompok dan tidak percakapan mereka tidak ingin diketahui oleh orang lain yang bukan dalam kelompok mereka. Seperti dalam kelompok apoteker mereka menggunakan istilah ruu untuk menyebutkan "obat yang sudah lama”, ruunaoshi "obat daur ulang", maakisuru "menempatkan obat daur ulang” (Mizuno, 1985 dalam Sanada, 1992: 27).

Dalam kelompok pencuri, kosa kata kau diartikan dengan mencuri, saru "tawanan". Serta dalam dunia kedokteran mereka menggunakan istilah essen untuk orang yang sedang puasa/tidak makan yang diambil dari bahasa Jerman "essen" "makan”, serta menggunakan hirou apabila menemukan pasien yang meninggal pada saat bertugas. Pembetukan kata hirou diambil dari suteru yang merupakan antonim dari kata hirou, serta suteru diambil dari bahasa Jerman "sterben" yang berarti "meninggal”.

Dalam dunia kepolisian menggunakan istilah geso o toru apabila mengambil jejak kaki pelaku di TKP, kata geso mempunyai makna geta atau "sesuatu yang dipakai di kaki". Serta menggunakan istilah butabako untuk "sel". Kata butabako diambil dari kata buta yang berarti "babi" dan bako yang berarti "kotak", jadi kata butabako secara leksikal "kotak babi" yang merupakan perumpaan dari "sel". Selanjutnya, menggunakan istilah takatobi untuk buronan yang melarikan diri ke luar negeri. Kata takatobi diambil dari kata takai yang berarti "tinggi" serta tobu yang berarti "terbang", jadi kata takatobi secara leksikal bermakna "terbang tinggi” yang merupakan kata sandi untuk buronan yang melarikan diri.

\subsection{Pembentukan ingo (kata sandi)}

Mikami Kenta mengkalisifikan pembentukan ingo ke dalam beberapa cara yaitu:

1. 音節省略 Onsetsu shouryaku (Pemendekan silabel / singkatan)

警察庁長官 Keisatsuchouchoukan $\rightarrow$ 長官 choukan

2. 音節転換 Onsetsu tankan (Penukaran silabel)

粉 Kona $\rightarrow$ なこ nako

3. 形状類似 Keijou ruiji

(Bentuk yang mirip)

針 Hari (jarum) $\rightarrow$ 松葉 matsuba (daun pohon pinus)

4. 色彩類似 Shikisai ruiji

(Warna yang sama)

刺青 irezumi $\rightarrow$ 墨 sumi

5. 連想 Rensou (Asosiasi)

はさみ Hasami (gunting) $\rightarrow$

かに kani (kepiting)

6. 動作 Dousa (Gerak)

職務質問 shokumushitsumon (bertanya) $\rightarrow$

ばんかけ bankake (menginterogasi)

7. 比喻 Hiyuu (Perumpamaan)

アオオニ aooni $\rightarrow$

青キップ aokippu (kertas tilang)

8. 音の疎通 Oto no sotsuu

(Bunyi yang sama)

聞 $<K i k u \quad \rightarrow$ 菊 $k i k u$ 
Izumi, Volume 5, No 1, 2016

e-ISSN: 2502-3535, p-ISSN: 2338-249X

Tersedia online di http://ejournal.undip.ac.id/index.php/izumi

9. 字謎 Jinazo (Permainan huruf) 酒 Sake ーサンズイ sanzui

10.不調 Fuchou (Symbol)

$$
\text { トイレToire 一突き当たり tsukiatari }
$$

11.類推 Ruisui (Analogi)

通話コード tsuwakoudo $\rightarrow$

無線暗号 musenango

\subsection{Pembentukan ingo dalam dunia kepolisian}

Dari beberapa data yang didapatkan ingo (kata sandi) dalam dunia kepolisian dapat diklasifikasikan sebagai berikut:

\section{a) Pemendekan silabel atau penyingkatan}

Pemendekan ini dilakukan dengan cara mengambil fonem atau suku kata awal di setiap kata atau hanya mengambil silabel awal atau akhir.

Contoh :

1. Eichi $(\mathrm{H})$ diambil dari kata Heroin

2. Tanpan (単犯) diambil dari kata tandokuhan 単独犯 yang bermakna kejahatan yang dilakukan seorang diri

3. Doukouhou (道交法) diambil dari kata dourou koutsuu kizokuhou 道路交通規則法 yang bermakna peraturan lalu lintas

4. Benroku ( 弁 録) diambil dari kata benkairokushusho 弁解録取書 yang bermakna berkas pengambilan rekaman pembelaan diri

5. Gasujuu (ガス銃) diambil dari kata sairui gasujuu 催涙ガス銃 yang bermakna gas air mata

\section{b) Penukaran silabel}

Contoh :

1. Obuke, pembentukannya dengan cara menukar silabel kei dengan bu dari kata bukei 警部 dengan membuang fonem [i] pada akhir kata serta menambahkan fonem [o] pada awal kata. Kata ini bermakna kepolisian

2. Satsukan (察官), pembentukannya dengan cara menukar silabel kan dengan satsu dari kata keisatsu 警官 (kepolisian).

3. Nako, pembentukannya dengan cara menukar silabel ko dengan na dari kata kona 粉 (tepung). Bentuk tepung yang mirip dengan heroin sehingga kata ini bermakna heroin.

\section{c) Bentuk yang mirip}

Contoh :

1.Aofuda 青札, fuda/satsu (label) mempunyai bentuk atau sama dengan kippu, sehingga digunakan sebagai ingo (kata sandi) untuk aokippu 青キップ (kertas tilang warna biru). Sama halnya dengan akafuda 赤札 menjadi akakippu 赤キップ (kertas tilang warna merah)

2.Piidan( $\mathrm{P}$ 弾), $\mathrm{P}$ merupakan singkatan dari powder (bubuk) dan dan 弾 (peluru), sehingga kata ini bermakna peluru gas air mata yang berbentuk serbuk

3.Fuda フダ(札), mempunyai bentuk yang sama atau sama dengan reijou 令状 (surat perintah.

\section{d) Asosiasi}

1. Geso ゲソ, yang bermakna 'geta atau sesuatu yang dipakai di kaki' diasosiasikan dengan ashi 足 (kaki) atau ashi ato 足跡 (bekas kaki), sehingga dipakai sebagai simbil untuk ashi ato 足跡 (bekas kaki).

2. Happa ハッパ, yang bermakna 'daun' diasosiakan dengan taima 大麻 (ganja) karena merupakan daun.

3. Heika no naka 塀の中, yang bermakna 'berada dalam sebuah tembok' diasosiakan dengan gokuchu 獄中 atau keimusho no naka 刑務所の中 (dalam penjara) dalam hal ini tembok diasosiakan dengan penjara karena sama-sama tidak bisa ditembus atau dalam keadaan terkurung.

4.Bessou 別荘, yang bermakna 'penginapan khusus' diasosiasikan dengan keimusho 刑務所 (penjara) karena merupakan penginapan khusus bagi orang-orang yang melakukan kejahatan atau terbukti melakukan kejahatan.

5. Mentai 面帯, yang bermakna 'tali yang dipasang di muka' diasosiasikan dengan sanso masuku 酸素 マスク (masker oksigen atau topeng zat azam)karena merupakan benda yang sama-sama dipakai pada wajah/muka. 
6.Geba ゲバ, yang diambil dari bahasa Jerman gebart yang bermakna 'kekerasan' diasosiasikan dengan rantou 乱闘 atau buryoku kuusou 武力抗争 (perkelahian kelompok) karena sama-sama mempunyai makna 'kekerasan atau perkelahian'

7.Men 面, yang bermakna 'wajah atau muka' diasosiasikan dengan atama 顔 (kepala) karena 'muka atau wajah' berada di kepala.

\section{e) Gerak}

1. Nobi ノビ, berasal dari pemendekan kata shinobikomi 忍び込 み yang berarti mengendap-endap. Oleh karena itu, digunakan sebagai sandi untuk kataku shinnyu 家宅侵入 (penyusupan dalam rumah), dengan kata lain orang yang melakukan penyusupan dengan sendirinya mengendap-endap.

2. Toru 取る (mengambil) digunakan sebagai sandi untuk taihousuru 逮捕する (menangkap, membekuk, menciduk) karena diasumsikan memiliki makna yang sama.

3. Tobu飛ぶ (terbang) digunakan sebagai sandi untuk nigeru 逃げる (melarikan diri) karena diasumsikan memiliki makna yang sama yakni tidak dapat lagi ditangkap.

4. Nagashi 流 L (aliran), digunakan sebagai sandi untuk 'pencuri yang mencari mangsa ditempat keramaian' karena diasumsikan memiliki makna seorang yang mencari buruan ditempat yang mempunyai 'aliran' (keramaian/orang yang lalu-lalang).

5. Oyogaseru 泳がせる (menyuruh berenang), digunakan sebagai sandi untuk kakuhou sesuni kanshinsuru 確保せずに監視する (penjagaan tanpa persiapan), karena diasumsikan memiliki makna yang sama.

\section{f) Perumpamaan}

1. Ao oni, dipakai sebagai sandi untuk aokippu 青キップ (Kertas tilang warna biru). Kippu (kertas tilang) diumpakan sebagai oni (setan) karena merupakan sesuatu hal yang menakutkan. Sama halnya dengan aka oni yang digunakan sebagai sebagai sandi untuk aka kippu 赤キップ (kertas tilang warna merah).

2. Takatobi 高飛び, dipakai sebagai sandi untuk kokugai toubou 国外逃亡 (melarikan diri ke luar negeri). Pelaku kejahatan (buronan) yang melarikan diri keluar negeri diumpamakan orang yang terbang tinggi sehingga samasama tidak dapat lagi dijangkau atau ditangkap.

3. Hako ハコ (kotak), dipakai sebagai sandi untuk kouban 交番 pos polisi karena memiliki bentuk yang sama yakni berbentuk kotak.

4. Shima (島) (pulau), dipakai sebagai sandi untuk nawabari 縄張り (daerah operasi atau daerah kekuasaan). Nawabari diumpamakan sebagai sebuah pulau dimana seseorang yang berada tidak bisa keluar dari daerah tersebut.

5. Inu イヌ (anjing), dipakai sebagai sandi untuk supai スパイ (mata-mata). Seorang mata-mata yang melakukan penyelidikan diumpamakan sebagai seorang anjing yang mengendap-endap mencari mangsa.

\section{g) Bunyi yang sama}

1. Rajio ラジオ, digunakan sebagai sandi untuk musen insho 無銭飲食 (makan minum tanpa bayar). Pemendekan kata Musen insho 無銭飲食 menjadi musen 無銭 memiliki bunyi yang sama dengan musen 無線 (tanpa kabel) dianalogikan sama dengan musen housou 無線放送 (pemberitaan tanpa kabel) yang dianggap sama dengan rajio ラジオ (radio) karena merupakan sesuatu yang dapat memberikan informasi (berita) tanpa jaringan kabel.

\section{h) Permainan huruf}

1. Ninben ニンベン, digunakan sebagai sandi untuk gizou 偽造 (pemalsuan) karena huruf kanji untuk gi 偽 memiliki kanji dasar 偽 yang diistilahkan dengan ninben.

2. Sanzui サンズイ, digunakan sebagai sandi untuk oshoku jiken 污職事件(penyuapan) karena huruf kanji untuk $o$ atau yogoreru memilki kanji dasar 污 yang diistilahkan dengan sanzui.

\section{i) Symbol}

1. Tsukkomi 突っ込み, digunakan sebagai symbol untuk sandi koukan 強姦 (pemerkosaan), karena tsukkomi memiliki makna tercebur sama halnya dengan orang yang diperkosa.

2. Supiido スピード, digunakan sebagai symbol untuk kakusezai 覚醒剂 (obat 
Izumi, Volume 5, No 1, 2016

e-ISSN: 2502-3535, p-ISSN: 2338-249X

Tersedia online di http://ejournal.undip.ac.id/index.php/izumi

perangsang), karena sama-sama obat perangsang mempercepat terjadinya sesuatu.

3. Tауиu 太夫, digunakan sebagai symbol untuk higaisha 被害者 (korban), karena tayuu memiliki makna 'aktor kabuki' .

\section{j) Analogi}

1. Hitam adalah warna yang gelap (tidak bersih) sama dengan orang melakukan kejahatan arau 洗う (mencuci), digunakan sebagai sandi untuk mimoto nado o chousa suru koto 身元などを調査する事 (penyelidikan terhadap asal-usul seseorang), karena dianalogi seseorang mencuci sama halnya dengan membersihkan segala kotoran atau mencari segala hal yang berhubungan dengan orang diinterogasi.

2. Utau 歌う (menyanyi), digunakan sebagai sandi untuk jihaku 自白 atau jikyou suru 自 供する (mengaku), karena dianalogikan bahwa seseorang yang mengakui kesalahan atau kejahatan yang telah diperbuat sama dengan orang yang bernyanyi.

3. E 絵 (gambar), digunakan sebagai sandi untuk sakuhin 作戦 (siasat) atau keikaku 計
画 (rencana), karena dianalogikan bahwa sebuah siasat atau rencana sebagai sebuah gambaran terhadap apa yang akan dilakukan kedepannya.

4. Shiro 白 (warna putih), digunakan sebagai sandi untuk keppaku 潔白 atau mujitsu 無実 (tidak bersalah), karena dianalogikan bahwa warna putih adalah sesuatu yang bersih sama dengan orang yang tidak bersalah atau orang yang bersih dari kejahatan.

5. Kuro 黒 (warna hitam), digunakan sebagai sandi untuk hannin 犯人 (pelaku kejahatan), karena dianalogikan bahwa warna.

\section{PENUTUP}

Dari beberapa data yang didapatkan dapat disimpulkan bahwa pembentukan ingo yang berhubungan dengan kepolisian dari berbagai macam bentuk yaitu : pemendekan silabel, penukaran silabel, bentuk yang mirip, asosiasi, gerak, perumpamaan, bunyi yang sama, permainan huruf, symbol, dan analogi.

Dari pembentukan tersebut, pembentukan dengan cara pemendekan silabel merupakan cara yang paling banyak dilakukan untuk membetuk ingo yang berhubungan dengan kepolisian.

\section{DAFTAR PUSTAKA}

Fuji, Atsushi. 2008. Modeling Anchor Text and Classifyng Queries to Enhance Web Document Retrieval. Proceding of The $17^{\text {th }}$ International Word Wide Web Conference, pp 337-346

Fuse, Satoru. Ironi To Iu

Ingo.http://www.lang.nagoya-

u.ac.jp/proj/sosho/2/fuse.pdf

Kawakami, Makiko. Ingo ni okeru taogo no zougohou.

http://dspace.wul.waseda.ac.jp/ dspace/bitstream/2065/29441/1/Koku gogakuKenkyuToSiryo_27_Kawaka mi.pdf

Kimura, Tomoaki. 2008. Hyouban Jouhou no Kensaku ni Okeru Ingoteki Zougohou no ouyou. http://www.slis.tsukuba.ac.jp/grad/ass ets/files/pub/2008/kimura.pdf

Kimura, Tomoaki and Fuji, Atsushi. 2009. Hyouban Jouhou no Kensaku ni
Okeru Ingoteki Zougohou no ouyou. Happyou Ronbunshu. http://www.cl.cs.titech.ac.jp/ fujii/paper/nlp2009kimura.pdf

Mahsun, M.S. 2001. MetodePenelitian Bahasa (Edisi Revisi). Jakarta: Rajawali Pers.

Mikami, Kenta. Hyouban Jouhou no Kensaku ni Okeru Ingoteki Zougohou no ouyou.

http://nlp.dse.ibaraki.ac.jp/ shinnou/z emi2009/nenji/nenji-mikami0508.pdf

Outa, Yuuki and Fuji, Atsushi. 2011. Hyouban Jouhou no Kensaku ni Okeru Ingo no Seisei to junizuke. The Assosiation for natural Language Processing. Pp 1147-1150

Sudaryanto. 1993. Metode dan Teknik Analisis Bahasa. Yogyakarta: Duta Wacana University Press 